\title{
The effect of information and communication technology (ICT) in Jordanian learning
}

\author{
Fawzi Altaany*, Farah Hanna Zawaideh** \\ *Department of management information system, Irbid National University, Irbid - JORDAN \\ ** Department of management information system, Irbid National University, Irbid - JORDAN
}

\begin{abstract}
Information and communication Technology are used of electronic means which involve access storage, processing of electronic technology to handling of information, the various forms of uses it's in order to improve Jordanian learning. The study aimed to investigate the uses and effect of ICTs for Jordanian learning from their perspective of student of higher school at the north of Jordan. The study method was a descriptive survey which uses questionnaire to collect data, questionnaire was justified and developed by the researcher to measure the effect of ICTs based on previous studies its applied to (548) student of higher school. The study was using SPSS to analyses data. The results indicate that ICTs for higher school at the north of Jordan there were a statistically significant relationship between the higher school at the north of Jordan and Jordanian learning, and seven of hypotheses reported statistically significant in the hypotheses and accepted but three hypotheses reported no a statistically significant and rejected. The study have Conclusion should gives more attention to focus on and beneficial of using ICTs applications.
\end{abstract}

Keywords: Information and communication technology (ICTs), Jordanian learning, higher school, Jordan.

\section{INTRODUCTION}

Information and communication technology (ICTs) are effected our life over the world and changes their society. ICTs have an important part of most organizations, institutions and businesses these days [1]. Many researchers reveal that ICTs will bean important part of education and learning for this ear and next ears [2, 3]. ICT was influencing all aspects of life in the community in many areas including learning, because ICTs provided the members of the community with more opportunities in adapting learning to individual needs, the community is, forcing institutions respond to this style of innovation. Modern technology offers the means and tool of improving teaching and learning [4]. ICT was importance for learning; identifying the possible disadvantages and advantage of ICTs and integration of these technologies in learning should be improving the quality of learning. According [5] stated the value of ICT in education. Many studies have been conducted to investigate barriers to integration of technology in education [6]. According to [7] argue the potentials of ICT in increasing facilitate the acquisition and absorption of knowledge, offering developing countries as Jordan and to enhance educational systems. The study aimed to study the effect and investigate the uses ICTs for Jordanian learning.

\section{PURPOSE OF STUDY}

The Purpose of the study consists of the following: 1. Highlight the literatures on learning that related to ICTs.

2. Studying the use ICTs in learning environments to enhance technology integration.

3. Examine the current reality of ICTs and their effect on improving learning in Jordan.

4. To make recommendations to enhance the role of ICTs to improve learning.

\section{IMPORTANCE OF THE STUDY:}

The importance of this study comes from:

1. The importance of this study is to call for interaction with modern ICTs which is reflected in a positive way to improve learning in Jordan and become with information age

2. The study contributes to highlight the ICTs in the learning in Jordan to demonstrate the importance of use.

3 . The issue has not been addressed to research in the learning in Jordan.

4. This study working on recommendations after analyzing the results of research, as well as researchers can benefit from this study to active, Collaborative, Creative and Integrative learning

\section{PROBLEM OF THE STUDY}

At present in Jordan, learning institutions using ICTs for the development of learning from the traditional way to the modern way, evolution of 
ICTs are effects the learning institutions, these technologies having a significant impact on social development especially of learning [8]. At present, the Ministry of Education and Ministry of Higher Education in Jordan work on the development and improvement of education in Jordan to produce outputs learning efficient and effectiveness, the researchers was a university professor at Irbid National University one of Jordanian universities, researchers realized that most of human in learning institutions are using ICTs that was create more knowledgeable and satisfied with its. However, there are barriers of human users commonly face while using ICTs, the researcher tried to know and investigated of using information and communication technology and its effect on learning institutions at Jordan.

\section{HYPOTHESES OF THE STUDY}

In order to address the problem of study and achieve its goals, hypotheses were developed as follows:

H1: There is a significant statistical between using ICTs and Jordanian learning from perspective of students.

$\mathrm{H} 2$ : There is a significant statistical between using ICTs and Flexibility learning from perspective of students.

H3: There is a significant statistical between using ICTs and Empowerment learning from perspective of students

H4: There is a significant statistical between using ICTs and Consistent learning from perspective of students

H5: There is a significant statistical between using ICTs and Interactive learning from perspective of students

H6: There is a significant statistical between using ICTs and Collaborative learning from perspective of students

H7: There is a significant statistical between using ICTs and used to Facilitate understanding learning from perspective of students

H8: There is a significant statistical between using ICTs and used to give Instant feedback learning from perspective of students

H9: There is a significant statistical between using ICTs and Used for Self Assessment learning from perspective of students

H10: There is a significant statistical between using ICTs and used to assist students with certain Disabilities learning from perspective of student.

\section{LITERATURE REVIEW AND THEORETICAL BACKGROUND}

More and more studies have reviewed the literature on using information and communication technology and learning, its have concluded that it has great potential to effect the learning. ICTs is the automation of processes, controls, and information production using hardware, software, database and network communication to ensure smooth and efficient running of activities. It is using real time and online system [9]. ICTs effect and provided many opportunities in adapting learning to individual needs [10]. Many of research have argued more advantage to the quality of learning [11]. ICTs are empowerment individual in charge of their own learning, learning material can be flexibility and interactive in many way, and all students consistent get the same materials, the use of ICTs in learning develops many skills such as collaborating, Interactive, Give Instant feedback for individual, Collaborative, and used to Facilitate understanding $[12,13]$.

According to [14] [13] studied the Impact of Face book Usage on Undergraduate Students Performance in Irbid National University: Case Study, the result of their study shows the survey revealed that $77 \%$ of the students have an account on Face book. One of the main findings is that there was a significant relationship between gender and Face book usage and the study revealed that whenever the less time spent on Face book, the higher performance will be in grade point average. This was conducted by the negative correlation between time spent on Face book and the performance of undergraduate student. The study has seven hypotheses; two of them were rejecting against five acceptable hypotheses.

According to [15] were studied the" Barriers to the Successful Integration of ICT in Teaching and Learning Environments: A Review of the Literature" the paper aims to demonstrate, through research, the obstacles to the use of ICT in education may assist educators to overcome these barriers and become successful technology adopters in the future. This paper provides a metaanalysis of the relevant literature that aims to present the perceived barriers to technology integration in science education. The findings indicate that No one component in itself is sufficient to provide good teaching. However, the presence of all components increases the possibility of excellent integration of ICT in learning and teaching opportunities. Generally, this paper provides information and recommendation to those responsible for the integration of new technologies into science education. According to [16] studied the" The use of Information and Communications Technology in teaching and e-learning in the 
Caribbean" the paper aims is to capture perceptions of the use of Information and Communications Technology (ICT) in teaching and e-learning at The University of the West Indies Open Campus. The sample was sent to fifty-eight (58) Course Coordinators for their feedback. The selected Survey participants were on schedule for Semester II, 2012. The result were Eighty-five percent of respondents reported that ICT appropriately used can enhance teaching and learning while $55 \%$ of respondents reported that they would like to make more use of ICTs in their teaching, also the results confirmed the specifically at assessing the use of ICTs in teaching and e-learning, it appears that respondents have used an ample amount of ICTs in their teaching both face-to-face and online. This paper provides recommendation to that there are numerous opportunities for training in the use of ICTs and further, a need to train e-Lecturers who are already familiar with the technology to a comfortable level.

According to [17] they studied the" Information and communication technologies to raise quality of teaching and learning in higher education institutions" the paper aims is to to help higher education teachers know, and be able to deploy, certain information and communication technologies (ICTs) towards shifting from teachercentered pedagogy to learner-centered instruction for increased quality of teaching and learning.. The results highlight many benefits of integrating these technologies into teaching and learning, as proved by projects in elementary and high schools. It then lists ICTs that can be used successfully in higher education, explains what they are, and shows how and evidence of use. This paper provides recommendation to those suggestions of what can be done to implement their use as integral to the entire higher education effort.

\section{METHODOLOGY}

The study was used a descriptive survey design. The aimed of descriptive surveys is to collect detailed and factual information that describes an existing phenomenon [18]. The target population of the study was higher school at the north of Jordan. A sample of ten higher schools was chosen. A total sampling technique was used to select 548 personnel who provide response to a structured questionnaire design to solicit their view about the effect of Information and communication Technology in Jordanian learning.

The questionnaire was specifically designed and modify according to privies study to accomplish the objectives of the study. It's contained 48 questions that measure the effect of Information and communication Technology in Jordanian learning. The Ordinary Least Square method (OLS) was used in analysis which comprises various tests such as t-test, f-test, r2 and the adjusted $\mathrm{r} 2$.

\section{RESULTS}

Hypotheses H1: There is a significant statistical between using ICTs and Jordanian learning from perspective of students. This hypothesis was examined by a model as shown in Tables $(1,2)$ where it was statistically significant, where $\mathrm{p}=.000$, $\mathrm{R}=0.589$, and $\mathrm{R} * 2=0.578$ Since $\mathrm{p}$ is less than 0.05 , there is a statistically significant relationship between ICTs and Jordanian learning from perspective of students, and thus hypotheses examine the all variable of the study it is accepted. Hypotheses H2: There is a significant statistical between using ICTs and Flexibility learning (Fle) from perspective of students. This hypothesis was examined by a model as shown in Tables (3) where it was statistically significant, where $\mathrm{p}=.0 .005$, Since $p$ is less than 0.05 ,there is a statistically significant relationship between ICTs and Flexibility of learning from perspective of students , and thus it is accepted.

Hypotheses H3: There is a significant statistical between using ICTs and Empowerment learning (Emp) from perspective of students. This hypothesis was examined by a model as shown in Tables (3) where it was statistically significant , where $p=.0 .000$, Since $p$ is less than 0.05 ,there is a statistically significant relationship between ICTs and Empowerment learning from perspective of students, and thus it is accepted

Hypotheses H4: There is a significant statistical between using ICTs and Consistent learning (Con) from perspective of students. This hypothesis was examined by a model as shown in Tables (3) where it was statistically significant, where $\mathrm{p}=.0 .001$, Since $\mathrm{p}$ is less than 0.05 , there is a statistically significant relationship between ICTs and Consistent learning from perspective of students , and thus it is accepted

Hypotheses H5: There is a significant statistical between using ICTs and Interactive learning (Int) from perspective of students. This hypothesis was examined by a model as shown in Tables (3) where it was statistically significant, where $\mathrm{p}=.0 .001$, Since $\mathrm{p}$ is less than 0.05 ,there is a statistically significant relationship between ICTs and Interactive learning from perspective of students , and thus it is accepted

Hypotheses H6: There is a significant statistical between using ICTs and Collaborative learning (Coll) from perspective of students. This hypothesis was examined by a model as shown in Tables (3) where it was statistically significant, where $\mathrm{p}=.0 .010$, Since $\mathrm{p}$ is less than 0.05 , there is a statistically significant relationship between ICTs 
and Collaborative learning from perspective of students, and thus it is accepted

Hypotheses H7: There is a significant statistical between using ICTs and used to Facilitate understanding learning (UFU) from perspective of students This hypothesis was examined by a model as shown in Tables (3) where it was statistically significant, where $\mathrm{p}=.0 .010$, Since $\mathrm{p}$ is less than 0.05 , there is a statistically significant relationship between ICTs and used to Facilitate understanding learning from perspective of students, and thus it is accepted

Hypotheses H8: There is a significant statistical between using ICTs and used to give Instant feedback learning (UGF) from perspective of students. This hypothesis was examined by a model as shown in Tables (3) where it was statistically significant, where $\mathrm{p}=.0 . .510$, since $\mathrm{p}$ is greater than 0.05 , there is a no statistically significant relationship between ICTs and used to give Instant feedback learning from perspective of students, and thus it is reject.

Table (1) Model Summary

\begin{tabular}{|l|l|l|l|l|}
\hline Model & R & R Square & Adjusted R Square & Std. Error of the Estimate \\
\hline 1 & $\mathbf{. 8 7 8}(\mathbf{a})$ & $\mathbf{. 5 7 8}$ & $\mathbf{. 7 7 6}$ & $\mathbf{. 5 2 4 4 4}$ \\
\hline
\end{tabular}

Hypotheses H9: There is a significant statistical between using ICTs and Used for Self Assessment learning (USA) from perspective of students. This hypothesis was examined by a model as shown in Tables (3) where it was statistically significant, where $p=.0 .635$, since $p$ is greater than 0.05 , there is a no statistically significant relationship between ICTs and Used for Self Assessment learning from perspective of students, and thus it is reject.

Hypotheses H10: There is a significant statistical between using ICTs and used to assist students with certain Disabilities learning (UASCD) from perspective of students. This hypothesis was examined by a model as shown in Tables (3) where it was statistically significant, where $\mathrm{p}=.6 .626$, since $\mathrm{p}$ is greater than 0.05 , there is a no statistically significant relationship between ICTs and assist students with certain Disabilities learning from perspective of students, and thus it is reject.

Table (2) ANOVA(b)

\begin{tabular}{|l|l|l|l|l|l|l|}
\hline Model & & Sum of Squares & df & Mean Square & F & Sig. \\
\hline 1 & Regression & $\mathbf{1 4 4 1 . 2 6 7}$ & $\mathbf{8}$ & $\mathbf{1 5 5 . 4 0 8}$ & $\mathbf{5 2 6 . 7 7 5}$ & $\mathbf{. 0 0 0 ( a )}$ \\
\hline & Residual & $\mathbf{4 3 . 5 3 3}$ & $\mathbf{9 6}$ & $\mathbf{. 4 1 0}$ & & \\
\hline & Total & $\mathbf{1 3 6 4 . 8 0 0}$ & $\mathbf{8 9}$ & & & \\
\hline
\end{tabular}

a Predictors: (Constant), JL, Emp, Fle, Con, Int, Coll, UFU, UGF, USA, UASCD

Table (3) Coefficients(a)

\begin{tabular}{|l|l|l|l|l|l|l|}
\hline $\begin{array}{l}\text { mode } \\
1\end{array}$ & \multicolumn{2}{l|}{$\begin{array}{l}\text { Unstandardized } \\
\text { Coefficients }\end{array}$} & $\begin{array}{l}\text { Standardized } \\
\text { Coefficients }\end{array}$ & t & Sig. \\
\hline & & B & Std. Error & Beta & B & Std. Error \\
\hline 1 & Constant & -.312 & .413 & & -1.216 & .182 \\
\hline & JL & .314 & .062 & .286 & 6.626 & .000 \\
\hline & Emp & .416 & .061 & .461 & 6.832 & .000 \\
\hline & Fle & .030 & .029 & .031 & 1.033 & .005 \\
\hline & Con & .059 & .030 & .066 & 1.977 & .001 \\
\hline & Int & .016 & .022 & .019 & .707 & .002 \\
\hline & Coll & 1.029 & .028 & .5480 & 36.139 & .010 \\
\hline & UFU & -.438 & .059 & -.519 & -7.449 & .000 \\
\cline { 2 - 7 } & UGF & .414 & .062 & .486 & $\mathbf{6 . 6 2 6}$ & .510 \\
\hline & USA & .416 & .061 & .461 & 6.832 & .635 \\
\hline & UASCD & .414 & .062 & .486 & 6.626 & .512 \\
\hline
\end{tabular}

a Dependent Variable: ICT

\section{CONCLUSIONS}

Estimation and assessing the effect of ICTs in Jordanians learning is a way to identify variables that are the most important to the learning environment and to what is necessary to facilitate Learning. Information Technology is the automation of processes, controls, and information production using hardware, software, database and network communication to ensure smooth and 
efficient running of activities. It is using real time and online system[19]. While ICTs play a critical role in any organization and affects their organizations, however ICTs affects their work and lead to draws them to obtain efficiency and effectiveness resulting in increase the learning.

Based on the results of this study it can be concluded that there are numerous opportunities for use of ICTs in Jordanian learning these opportunities like empowerment, flexibility, consistent, interactive, collaborative and used to facilitate understanding and these variable are already not familiar with the ICTs like used to give instant feedback, used for self assessment and used to assist students with certain disabilities.

Since it is anew technology for Jordanians learning face many challenges in using it in higher school because of several reasons such as lack of training on the accurate way to use these technologies in addition to the lack of clear information about benefits of using ICTs applications for Jordanians learning. Recently there is a good movement toward enhancing Jordanians learning to make use of this vital and valuable technology.

\section{REFERENCES}

[1]. Zhang, P., \& Aikman, S. "Attitudes in ICT Acceptance and use". In J. Jacko (Ed.), Human-Computer Interaction, Part I. Syracuse, NY: Springer-VerlagBerlin Heidelberg pp. 1021-1030), 2007.

[2]. Grimus, M. "ICT and multimedia in theprimary school". Paper presented at the 16th conference oneducational uses of information and communication technologies, Beijing, China, pp $21-25$ Aug, 2000.

[3]. Yelland, N.. "Teaching and learning with information and communication technologies (ICT) for innumeracy in the early childhood and primary years of schooling. Australia: Department of Education, Training and Youth Affairs, 2001.

[4]. Lefebvre, S., Deaudelin, D., \& Loiselle, J. "ICT implementation stages of primary school teachers: The practices and conceptions of teaching and learning" Paper presented at the Australian Association for Research in Education National Conference, Adelaide, Australia, 27th - 30thNovember, 2006.

[5]. Balanskat, A., Blamire, R., \& Kefala, S. A review of studies of ICT impact on schools in Europe: European School net, 2006.

[6]. Al-Alwani, A. "Barriers to Integrating Information Technology in Saudi Arabia
Science Education. Doctoral dissertation, the University of Kansas, Kansas, 2005.

[7]. Esfahanian, A. Javaheri, and M. Ghaffarpour, "Thermal analysis of an SI engine piston using different combustion boundary condition treatments", Applied Thermal Engineering,vol.26,p Esfahanian, A. Javaheri, and M. Ghaffarpour, "Thermal analysis of an SI engine piston using different combustion boundary condition treatments", Applied Thermal Engineering,vol.26,pp.277-287,2006.",

Surface and Coatings Technology,vol. 203, pp. 91-98, 2008.

[8]. Tinio, V.L. "ICT in Education: UN Development Programmed. (Retrieved from http:www.eprmers.org on December 2009.

[9]. Fogg, P" what to do when home is just another word for the office', Chronicle of Higher Education, vol. 54 (21), p12, 2010

[10]. Adeoti, J.O "Information Technology Investment in Nigerian Manufacturing Industry: The Progress So Far", Selected Papers for the 2004 Annual Conference, Ibadan: Nigerian Economic Society, p 213244, 2005.

[11]. Yousef, A. B. and Dahamini, M "The Economics of E- Learning: The Impact of ICT on Student Performance in Higher Education": Direct Effects, Indirect Effects and Organizational Change 2005.

[12]. Al-Ansari, H. Internet use by the faculty members of Kuwait University. The Electronic Library 24, pp 791-803, 2006.

[13]. Newton, L. and Rogers, L. "Thinking frameworks for planning ICT in science lessons" School Science Review, 84, 309, 113-120., 2003.

[14]. Bhattacharya, I. \& Sharma, K. 'India in the knowledge economy - an electronic paradigm', International Journal of Educational Management Vol. 21 No. 6, Pp. 543- 568, 2007.

[15]. Altaany, and Jassim, Impact of Face book Usage on Undergraduate Students Performance in Irbid National University: Case Study, International Journal of Engineering Research and Applications (IJERA) 3(4), , p 255-260, 2012.

[16]. Bingimlas Khalid Abdullah "Barriers to the SuccessfulIntegration of ICT in Teaching andLearning Environments: A Reviewof the Literature Eurasia Journal of Mathematics, Science \& Technology Education, 5(3), 235245, 2009

[17]. Masino, Monica "The use of Information and Communications Technology in 
teaching and e-learning" in the Caribbean Journal of Instructional Pedagogies Authors retain the copyright to the manuscripts published in AABRI journals. Please see the AABRI Copyright Policy at http://www.aabri.com/copyright.html.1-9p 2010.

[18]. Njọkụ ,Chris Prince Udochukwu "Information and communication technologies to raise quality of teaching and learning in higher education institutions" International Journal of Education and Development using Information and Communication Technology (IJEDICT), Vol. 11, Issue 1, pp. 122-147, 2015.

[19]. Adeoti, J.O () "Information Technology Investment in Nigerian Manufacturing Industry: The Progress So Far", Selected Papers for the 2004 Annual Conference, Ibadan: Nigerian Economic Society, p213244, 2005 